\title{
LETTER
}

\section{Night-time intensivists - waste of resources or failure of process optimization?}

Jukka Takala

See related commentary by Levy, http://ccforum.com/content/17/5/1008

Dr Levy [1] commented on the study of Kerlin and colleagues [2] on the relevance, or futility, of night-time intensivists. Kerlin and colleagues compared in-hospital night-time intensivist presence with night-time phone consultations by daytime intensivists (control) with regard to ICU length of stay, hospital mortality, and readmission rate. Randomized 7 day blocks of night-time intensivist presence versus control had no effect. Previously, Dr Levy found no association between high-intensity daytime staffing and mortality, and no benefit of night-time intensivists in high-intensity ICUs in a retrospective study [3]. Dr Levy suggests that 'it is time...to redirect the resources proposed for night-time intensivists elsewhere'. Conclusions on night-time intensivists, based on these two studies $[2,3]$ may be misleading and premature.

Failure of specific resources in the ICU to influence outcomes is nothing new - monitoring technologies offer a prime example [4]. Resources, per se, make no difference, whereas their correct use may. The same applies for human resources. Intensivist presence in the night-time is unlikely to influence length of stay or other outcomes, unless the processes within and beyond the ICU have been adjusted to profit from professional night-time decision-making. For example, weaning practices, decision and timing of extubation, and administrative delays in discharging patients can have a major impact on ICU length of stay. A few hours delay in extubation may prolong the ICU stay by 1 day. The difficulties in changing care processes are well known. For this, more than one intensivist is necessary. However, increased intensivist presence can enhance the optimization of multiple processes relevant to resource utilization and outcome [5].

Limited resources should be used optimally. Intensivist presence should be evaluated in the context of care processes - a failure to influence the process will inevitably fail to influence outcomes.

\section{Authors' response}

Mitchell M Levy

I appreciate the insightful comments of Professor Takala. Except for the 'misleading' comment, I agree with him: it is premature to draw any firm conclusions about the value of night-time intensivists from the current published literature. And yet, as I describe in my commentary, many in the field advocate for nighttime intensivists, and many institutions have already adopted that model, at significant expense. This is true, despite the failure of the two most recently published studies, both in the New England Journal of Medicine, to convincingly demonstrate the beneficial impact of night-time intensivists on patient outcomes. The Kerlin study [2] was a negative randomized controlled trial, and the effect on outcomes observed in the

Correspondence: jukka.takala@insel.ch

Department of Intensive Care Medicine, University Hospital Bern (Inselspital), $\mathrm{CH}-3010$, Bern, Switzerland
Wallace study [6] was limited to a small number of hospitals.

As Professor Takala pointed out, these uncertain outcomes may be because the processes of care in the institutions involved in published studies may not have been properly tailored to maximize impact from the presence of night-time intensivists. If this is the case, my assertion that it is premature to direct scarce resources to the hiring of night-time intensivists is even more accurate. Given the fiscal constraints evident in global health care systems, it is our responsibility as clinicians, researchers and administrators to direct resources to initiatives that are of proven benefit.

\section{Competing interests}

The authors declare that they have no competing interests. 


\section{References}

1. Levy MM: Intensivists at night: putting resources in the right place. Crit Care 2013, 17:1008

2. Kerlin MP, Small DS, Cooney E, Fuchs BD, Bellini LM, Mikkelsen ME, Schweickert WD, Bakhru RN, Gabler NB, Harhay MO, Hansen-Flaschen J, Halpern SD: A randomized trial of nighttime physician staffing in an intensive care unit. N Engl J Med 2013, 368:2201-2209.

3. Levy MM, Rapoport J, Lemeshow S, Chalfin DB, Phillips G, Danis M: Association between critical care physician management and patient mortality in the intensive care unit. Ann Int Med 2008, 148:801-809.

4. Vincent JL, Pinsky MR, Sprung CL, Levy M, Marini JJ, Payen D, Rhodes A, Takala J: The pulmonary artery catheter: in medio virtus. Crit Care Med 2008, 36:3093-3096.

5. Jakob SM, Lubszky S, Friolet R, Rothen HU, Kolarova A, Takala J: Sedation and weaning from mechanical ventilation: effects of process optimization outside a clinical trial. J Crit Care 2007, 22:219-228.

6. Wallace DJ, Angus DC, Barnato AE, Kramer AA, Kahn JM: Nighttime intensivist staffing and mortality among critically ill patients. N Engl J Med 2012, 366:2093-2101.

\section{$10.1186 / \mathrm{cc} 13170$}

Cite this article as: Takala: Night-time intensivists - waste of resources or failure of process optimization? Critical Care 2013, 17:472 